\title{
A Comparative Study of Intrathecal Isobaric Ropivacaine with Different Doses of Clonidine in Lower Extremity Surgery
}

\author{
Authors \\ Dr Nihar Sharma ${ }^{1}$, Dr Bhawani Singh ${ }^{2}$, Dr Trishla Jain ${ }^{3}$, Dr Siddharth Sharma ${ }^{4}$ \\ ${ }^{1,2,3,4}$ Department of Anaesthesia, SMS Medical College, Jaipur, India \\ Corresponding Author
}

Dr Bhawani Singh c/o Dr Nihar Sharma

376, Barkat Nagar, Gali Number 10, Tonk Phatak, Jaipur

Phone no.9314044376, Email: drniharsharma@gmail.com

\begin{abstract}
Aim: To compare the clinical effects of combined doses of Ropivacaine and Clonidine.

Material and Methods: Ninety patients between 20-60 years, ASA I and II category who were posted for lower limb surgery were included in the study with informed consent and were randomly assigned to three groups. Group Ropivacaine $15 \mathrm{mg}$ (Group R), Group Ropivacine 15mg+Clonidine15 $\mu \mathrm{g}$ (Group R-C15), Group Ropivacaine 15mg + Clonidine $30 \mu \mathrm{g}$ (Group R-C30). Intraoperative hemodynamics, onset and duration of sensory and motor block, analgesia and adverse effects were noted.

Results: There was no significant difference in onset and quality of sensory and motor block in all three groups. Groups R-C15 and R-C30 had prolonged duration of sensory and motor block as compared to group $R$. Time for regression of sensory block upto L1 dermatome was significantly prolonged in Groups $R$ $C 15$ and R-C30 as compared to group R. Mean duration of complete and effective analgesia was in the order Group R-C30>Group R-C15>Group R and the difference was statistically significant.

Conclusion: Addition of clonidine $15 \mu \mathrm{g}$ and $30 \mu \mathrm{g}$ to intrathecal ropivacaine produces dose dependent increase in the duration of sensory and motor blockade as well as duration of analgesia without affecting hemodynamics or safety.
\end{abstract}

Keywords: Intathecal, Ropivacaine, Clonidine, Lower extremity surgery.

\section{Introduction}

Spinal anesthesia is the most popular and preferred technique of regional anesthesia till date for short duration lower limb orthopedic surgical procedures because it is simple to perform, economical and produces rapid onset of anesthesia. Local anesthetics such as lignocaine and bupivacaine have been used for spinal anesthesia since many years. The search for newer local anesthetics continue because of the neurotoxic effects of lignocaine ${ }^{[1]}$ and cardiotoxic effect of bupivacaine ${ }^{[2]}$. Ropivac- aineis less toxic to the central nervous system and cardiovascular system and is widely used as an alternative to bupivacaine. The level of motor block is similar to bupivacaine, but with shorter duration and later onset of motor block ${ }^{[3]}$. To overcome these problems spinal additives can be used. Although many drugs (fentanyl, morphine, vasoconstrictors like epinephrine and phenylephrine, $\alpha 2$ - agonists) have been used as an additive to local anesthetics but high incidence of side-effects (respiratory depression, sedation, cardiovascular instability, 
nausea-vomiting, pruritus, and urinary retention) and relative ineffectiveness resulted in reluctance to administer these drugs. In clinical practice, clonidine is widely used as an adjuvant with local anesthetics for postoperative pain relief. Using clonidine to lower the dose of intrathecal ropivacaine possibly provides adequate intrathecal anesthesia, without compromising the benefits of early mobilization and voiding.

In present study we aimed to compare the clinical effects of adding two different doses of clonidine to intrathecal ropivacaine.

\section{Materials and Methods}

The study was done in 90 patients aged 20-60years, in the ASA I-II group undergoing lower extremity procedures. Permission from the institutional ethical committee and review board was obtained. Patients having history of any chronic illness (like hypertension, diabetes mellitus, cardiac disease etc.), chronic history of headache and backache ,spinal deformity or infection at local site, coagulopathy ,known history of hypersensitivity with local anaesthetics were excluded from study. All patients were assessed preoperatively and explained about the anaesthetic technique and perioperative course. Informed consent of the patients for the study was taken. An independent assistant was there to randomly assign a particular group to the patients.

Group Ropivacaine15mg (Group R, n=30, control group): Patients received $15 \mathrm{mg}$ of $0.75 \%$ isobaric Ropivacaine $+1 \mathrm{ml}$ normal saline, total volume $3 \mathrm{ml}$. Group Ropivacaine15mg +Clonidine $15 \mu \mathrm{g}$ (Group $\mathrm{R}-\mathrm{C} 15, \mathrm{n}=30$ ): Patients received $15 \mathrm{mg}$ of $0.75 \%$ isobaric Ropivacaine $+15 \mu \mathrm{g}$ Clonidine in $1 \mathrm{ml}$ normal saline, total volume $3 \mathrm{ml}$.

Group Ropivacaine15mg +Clonidine $30 \mu \mathrm{g}$ (Group R-C30, n=30): Patients received $15 \mathrm{mg}$ of $0.75 \%$ isobaric Ropivacaine $+30 \mu \mathrm{g}$ Clonidine in $1 \mathrm{ml}$ normal saline, total volume $3 \mathrm{ml}$.

After taking informed consent and confirming overnight fasting, patients were shifted to operation theatre. Baseline vitals like B.P., pulse rate, respiratory rateetc. were recorded. After securing an $18 \mathrm{G}$ intravenous cannula, preloading was done with $10-20 \mathrm{ml} / \mathrm{kg}$ Lactated Ringer solution.
Vitals just before lumbar puncture were noted. Lumbar puncture was performed in sitting position at L3-L4 interspace with $25 \mathrm{G}$ quincke needle under strict aseptic conditions and the drug was given intrathecally at the rate of $1 \mathrm{ml} / 10 \mathrm{sec}$ according to the allocated group. Patients were turned supine immediately after the injection. A pillow was placed under the shoulder. The patients were given 4.0 L/min of oxygen by venti- mask.

The following parameters were monitored in the perioperative period: Onset of sensory block, level of sensory block, duration of sensory block, onset of motor block, duration of motor block, hemodynamic changes, duration of complete and effective analgesia and adverse effects. Onset of sensory block was defined as the time from the intrathecal injection of the study drug to the time taken to achieve anesthesia to pin prick at L1 dermatomal level. Hypotension was defined as systolic blood pressure below 90mmhg and bradycardia defined as fall in heart rate below 60 beats per min.

\section{Observation and Results}

Table 1. Mean demographic data in groups

\begin{tabular}{|l|c|c|c|c|}
\hline & $\begin{array}{c}\text { Group R } \\
\text { Mean } \pm \\
\text { SD) }\end{array}$ & $\begin{array}{c}\text { Group R }- \\
\text { C15 } \\
(\text { Mean } \pm \\
\text { SD) }\end{array}$ & $\begin{array}{c}\text { Group R- } \\
\text { C30 } \\
\text { (Mean } \pm \\
\text { SD) }\end{array}$ & \\
\hline Age (in years) & $\begin{array}{c}39.03 \pm \\
11.09\end{array}$ & $\begin{array}{c}41.60 \pm \\
12.42\end{array}$ & 39.13 & $\mathrm{p}>0.05$ \\
& $71.33 \pm$ & $70.23 \pm 10.66$ & $68.67 \pm 10.3$ & $\mathrm{p}>0.05$ \\
\hline Weight(in kg) & 10.25 & 20 & & $\mathrm{p}>0.05$ \\
\hline Height(in cm) & $169.83 \pm 8$. & $\begin{array}{c}169.03 \pm 8 . \\
02\end{array}$ & $168.43 \pm 7.81$ & \\
\hline Surgery duration & $81.66 \pm 13$. & $88.03 \pm 18$. & $81.0 \pm 16.81$ & $\mathrm{p}>0.05$ \\
(in minutes) & 33 & 36 & & \\
\hline M:F ratio & $23: 7$ & $4: 1$ & $4: 1$ & \\
\hline ASA grade(I:II) & $14: 1$ & $9: 1$ & $9: 1$ & \\
\hline
\end{tabular}

No statistically differences between patient demographics and surgery duration were found between the three groups (table1).

Table 2. Sensory block (in minutes)

\begin{tabular}{|l|c|c|c|}
\hline Group & $\begin{array}{c}\text { Onset of } \\
\text { sensory block }\end{array}$ & $\begin{array}{c}\text { Time to achieve } \\
\text { highest level of } \\
\text { sensory block }\end{array}$ & $\begin{array}{c}\text { Mean time to } \\
\text { regression upto } \\
\text { L1 dermatome }\end{array}$ \\
\hline R & $6.97 \pm 1.54$ & $11.10 \pm 1.70$ & $129 \pm 9.59$ \\
\hline R-C15 & $6.73 \pm 1.85$ & $10.57 \pm 1.85$ & $146.17 \pm 2.64$ \\
\hline R-C30 & $6.50 \pm 1.95$ & $10.17 \pm 2.30$ & $153.67 \pm 14.73$ \\
\hline
\end{tabular}

In present study there was no significant difference in mean time of onset of sensory block [ $p>0.05$ ] and time to achieve highest level of sensory block between the groups [p $>0.05]$. The mean time of 


\section{JMSCR Vol||05||Issue||09||Page 27472-27477||September}

onset of sensory block and mean time to achieve highest level of sensory block between the different groups were found to be comparable and statistically insignificant. Results of our study coincides with studies by De Kock et al, Chen xinzhong et al. and Ying Y. Lee et al ${ }^{[4],[5],[6]}$.
In present study there was significant difference in time of sensory block regression to $\mathrm{L} 1$ dermatome in three groups $(\mathrm{p}<0.05)$. It was earlier in group $\mathrm{R}$

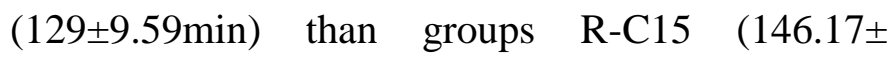
$12.64 \mathrm{~min})$ and group R-C30 (153.67 $\pm 14.73 \mathrm{~min})$. Results of our study coincide with Gonul Sagiroglu et al. \& Racle et al ${ }^{[7],[8]}$.

Table 3: Motor block

\begin{tabular}{|l|c|c|}
\hline Group & $\begin{array}{c}\text { Mean time to onset of } \\
\text { motor block(in minutes) }\end{array}$ & $\begin{array}{c}\text { Mean time to achieve complete } \\
\text { recovery of motor block(in minutes) }\end{array}$ \\
\hline R & $10.53 \pm 1.71$ & $125.83 \pm 10.51$ \\
\hline R-C15 & $10.07 \pm 1.60$ & $147.83 \pm 10.80$ \\
\hline R-C30 & $9.90 \pm 1.70$ & $153.33 \pm 13.94$ \\
\hline
\end{tabular}

There was no statistically significant difference among the study groups in time of onset of motor block $(p>0.05)$. In this study time to achieve maximum motor block was statistically not significant $(\mathrm{P}>0.05)$ between the groups. The duration of motor block was found to be significantly longer in Group R-C15 and Group RC30 compared to Group R ( $<<0.05)$.

Table 4: Analgesia

\begin{tabular}{|l|l|l|}
\hline Group & $\begin{array}{l}\text { Mean duration of complete } \\
\text { analgesia(in minutes) }\end{array}$ & $\begin{array}{l}\text { Mean duration of effective } \\
\text { analgesia(in minutes) }\end{array}$ \\
\hline R & $167.33 \pm 10.80$ & $198.50 \pm 13.96$ \\
\hline R-C15 & $199.67 \pm 11.59$ & $241.83 \pm 14.88$ \\
\hline Group R-C30 & $228.67 \pm 15.13$ & $273.17 \pm 19.76$ \\
\hline
\end{tabular}

Analgesia was measured as time from the intrathecal injection to the first feeling of pain (complete analgesia) and to the first request of analgesic (effective analgesia). In our study, duration of complete analgesia and duration of effective analgesia were more in clonidine added groups like in Group R-C30 (228.67 $\pm 15.13 \mathrm{~min}$ and $273.17 \pm 19.76 \mathrm{~min})$ and Group R-C15 (199.67 $\pm 11.5 \mathrm{~min}$ and $241.83 \pm 14.88 \mathrm{~min}$ ) than Group $\mathrm{R}$ $(167.33 \pm 10.80 \mathrm{~min}$ and $198.50 \pm 13.96 \mathrm{~min})$.

Table 5. Mean PR at different time intervals.

\begin{tabular}{|c|c|c|c|c|c|c|c|c|c|c|}
\hline \multirow[b]{2}{*}{ Group } & \multicolumn{10}{|c|}{ Level } \\
\hline & Basal & At $5 \mathrm{~min}$ & At $10 \mathrm{~min}$ & At $20 \mathrm{~min}$ & At $30 \mathrm{~min}$ & At $40 \mathrm{~min}$ & At $60 \mathrm{~min}$ & At $80 \mathrm{~min}$ & $\begin{array}{c}\text { At } 100 \\
\text { min }\end{array}$ & $\begin{array}{c}\text { At } 120 \\
\text { min }\end{array}$ \\
\hline $\mathrm{R}$ & $\begin{array}{r}85.43 \\
\pm 9.19 \\
\end{array}$ & $\begin{array}{l}87.27 \\
\pm 9.36 \\
\end{array}$ & $\begin{array}{c}96.20 \pm \\
9.99\end{array}$ & $\begin{array}{l}95.77 \\
\pm 4.93 \\
\end{array}$ & $\begin{array}{c}96.00 \pm \\
6.45\end{array}$ & $\begin{array}{c}94.73 \pm \\
5.87\end{array}$ & $\begin{array}{c}94.87 \pm \\
5.88\end{array}$ & $\begin{array}{c}96.90 \pm \\
4.65\end{array}$ & $\begin{array}{c}93.80 \pm \\
7.56\end{array}$ & $\begin{array}{c}93.27 \pm \\
6.89\end{array}$ \\
\hline R-C15 & $\begin{array}{c}85.73 \\
\pm 10.64 \\
\end{array}$ & $\begin{array}{r}90.27 \\
\pm 9.69 \\
\end{array}$ & $\begin{array}{r}95.37 \\
\pm 5.18 \\
\end{array}$ & $\begin{array}{r}94.93 \\
\pm 4.92 \\
\end{array}$ & $\begin{array}{r}94.90 \\
\pm 7.03 \\
\end{array}$ & $\begin{array}{r}95.17 \\
\pm 5.06 \\
\end{array}$ & $\begin{array}{r}94.17 \\
\pm 6.90 \\
\end{array}$ & $\begin{array}{r}94.80 \\
\pm 6.53 \\
\end{array}$ & $\begin{array}{r}95.67 \\
\pm 8.02 \\
\end{array}$ & $\begin{array}{r}94.67 \\
\pm 7.38 \\
\end{array}$ \\
\hline $\mathrm{R}-\mathrm{C} 30$ & $\begin{array}{c}85.87 \pm \\
9.18\end{array}$ & $\begin{array}{c}86.60 \\
\pm 12.01\end{array}$ & $\begin{array}{c}93.13 \pm \\
9.45\end{array}$ & $\begin{array}{c}92.10 \pm \\
8.32\end{array}$ & $\begin{array}{c}93.37 \pm \\
9.75\end{array}$ & $\begin{array}{c}91.07 \pm \\
9.63\end{array}$ & $\begin{array}{c}91.20 \pm \\
8.15\end{array}$ & $\begin{array}{c}92.90 \pm \\
7.55\end{array}$ & $\begin{array}{c}90.70 \pm \\
8.14\end{array}$ & $\begin{array}{c}89.63 \pm \\
7.48\end{array}$ \\
\hline
\end{tabular}

Table 5 shows mean pulse rate \pm SD at different There was no significant difference in pulse rate time periods. perioperatively between the groups.

Table 6. Mean Arterial Pressure at different time periods

\begin{tabular}{|c|c|c|c|c|c|c|c|c|c|}
\hline \multirow{2}{*}{ Group } & \multicolumn{9}{|c|}{ Level } \\
\hline & At $5 \mathrm{~min}$ & At $10 \mathrm{~min}$ & At $20 \mathrm{~min}$ & At $30 \mathrm{~min}$ & At $40 \mathrm{~min}$ & At $60 \mathrm{~min}$ & At $80 \mathrm{~min}$ & At $100 \mathrm{~min}$ & At $120 \mathrm{~min}$ \\
\hline Group R & $\begin{array}{l}87.49 \\
+7.02\end{array}$ & $\begin{array}{r}87.26 \\
\pm 6.81\end{array}$ & $\begin{array}{r}92.72 \\
+4.48\end{array}$ & $\begin{array}{r}91.74 \\
+5.69\end{array}$ & $\begin{array}{c}92.32 \\
+5.70\end{array}$ & $\begin{array}{l}91.69 \\
+363\end{array}$ & $\begin{array}{r}93.34 \\
+3.18\end{array}$ & $\begin{array}{l}93.79 \\
+3.54\end{array}$ & $\begin{array}{r}94.27 \\
+3.80\end{array}$ \\
\hline Group R-C15 & $\begin{array}{r}83.56 \\
+6.16\end{array}$ & $\begin{array}{r}84.44 \\
+3.62 \\
\end{array}$ & $\begin{array}{r}89.62 \\
+5.71\end{array}$ & $\begin{array}{r}90.13 \\
+4.39\end{array}$ & $\begin{array}{r}91.05 \\
+4.66\end{array}$ & $\begin{array}{r}90.95 \\
+4.41 \\
\end{array}$ & $\begin{array}{r}91.98 \\
+5.25\end{array}$ & $\begin{array}{r}92.26 \\
+5.52\end{array}$ & $\begin{array}{r}92.67 \\
+5.90\end{array}$ \\
\hline Group R-C30 & $\begin{array}{c}83.63 \pm \\
5.51\end{array}$ & $\begin{array}{c}84.12 \pm \\
5.80\end{array}$ & $\begin{array}{c}86.62 \pm \\
6.04\end{array}$ & $\begin{array}{c}89.50 \pm \\
4.29\end{array}$ & $\begin{array}{c}91.42 \pm \\
3.80\end{array}$ & $\begin{array}{c}90.03 \pm \\
3.57\end{array}$ & $\begin{array}{c}92.28 \pm \\
3.20\end{array}$ & $\begin{array}{c}91.38 \pm \\
3.74\end{array}$ & $\begin{array}{c}93.94 \pm \\
4.34\end{array}$ \\
\hline
\end{tabular}

As shown in table 6, there were no statistically groups in Mean Arterial Pressure at different time significant difference $(p>0.05)$ between the three periods. 
Table 7: Perioperative adverse effects

\begin{tabular}{|l|l|l|l|l|l|l|l|}
\hline \multirow{2}{*}{ Adverse effect } & \multicolumn{3}{l|}{ Group R } & \multicolumn{2}{l|}{$\begin{array}{l}\text { Group } \\
\text { R-C15 }\end{array}$} & \multirow{2}{*}{$\begin{array}{l}\text { Group } \\
\text { R-C30 }\end{array}$} \\
\cline { 2 - 8 } & No. & $\%$ & No. & $\%$ & No. & $\%$ & \\
\hline Hypotension & 2 & 6.66 & 3 & 10 & 5 & 16.66 & $>.05$ \\
\hline Shivering & 1 & 3.33 & 2 & 6.66 & 2 & 6.66 & $>.05$ \\
\hline Nausea & 2 & 6.66 & 2 & 6.66 & 2 & 6.66 & $>.05$ \\
\hline Bradycardia & 0 & 0 & 1 & 3.33 & 2 & 6.66 & $>.05$ \\
\hline
\end{tabular}

As shown in table 7 , there was no significant ( $\mathrm{p}>$

\subsection{5) difference in intraopreative adverse effects} like nausea, hypotension, bradycardia and shivering in between groups. There was no sedation, pruritis, urinary retention, respiratory depression and vomiting in any case.

\section{Discussion}

Clonidine is a selective partial agonist for $\alpha 2$ adrenoceptor. It is known to increase both sensory and motor block of local anaesthetics by $30-50 \%$. Prolongation of the duration of action of local anesthetics by Intrathaecal clonidine may result from local vasoconstriction and altered local anesthetic disposition or from a direct analgesic effect on $\alpha 2$-adrenoceptors in the substantia gelatinosa of the spinal cord. This effect has been reported using doses as high as 1 or $2 \mu \mathrm{gm} / \mathrm{kg}$. At these doses improved analgesia is associated with systemic side effects like sedation, hypotension and bradycardia. This study was conducted to compare the effect of $15 \mu \mathrm{g} \& 30 \mu \mathrm{g}$ of clonidine added to intrathecally administered isobaric ropivacaine $15 \mathrm{mg}(0.5 \%)$ with respect to onset \& duration of sensory \& motor block, hemodynamics, adequacy of analgesia \& associated side effect in lower extremity surgery. The demographic data such as age, sex, height and weight were comparable and had no influence on outcome of the study. Types of surgeries in all three groups were similar and were comparable amongst three groups.

Results of our study were similar to De Kock et al in which they administered low dose of ropivacaine $8 \mathrm{mg}$ with different doses of clonidine $(15,45,75 \mu \mathrm{g})$ for knee arthroscopy ${ }^{[4]}$. Gonulsagiroglu et al compared same dose of clonidine $15 \mu \mathrm{g} \& 30 \mu \mathrm{g}$ with ropivacaine $1 \%$ for lower extremity surgery and results were similar to our study ${ }^{[7]}$.

At the time of rescue analgesic, motor power was completely recovered in all the patients. Our results were similar to studies of McNamee et al. and Van Kleef et al. with regards to time taken to achieve maximum motor block and duration of motor block ${ }^{[9],[10]}$. Result of this study also coincide with Gonul Sagiroglu et al. as in their study the isobaric ropivacaine group showed a more rapid recovery from motor block compared with the ropivacaineclonidine groups $^{[7]}$. S Kurdi Madhuri et al used 0.75 isobaric ropivacaine in the dose range of $3.5-4.5$ $\mathrm{ml} \&$ found it safe in patients undergoing spinal anaesthesia for lower limb surgery. $3 \mathrm{ml}$ of $0.5 \%$ \& $0.75 \%$ isobaric ropivacaine has been used for lower limb surgery with patients showing a good quality of motor block with both concentrations ${ }^{[11]}$.

The quality of Intraoperative analgesia was quite good in all patients. No patient of any group complained of discomfort on skin incision. Analgesic effect of clonidine is contributed by various mechanisms. Neuraxial placement of clonidine inhibits spinal substance $\mathrm{P}$ release and nociceptive neuron firing produced by noxious stimulation. Substance P release inhibits the cGMP believed to be its antinociceptive effect ${ }^{[12]}$. Our results coincide with De Kock et al and b Gonul Sagiroglu et al. study as they showed that addition of clonidine to ropivacaine improves intraoperative anesthesia and significantly reduces the demand for postoperative analgesic ${ }^{[4],[7]}$.

Hypotension was the most frequent adverse effect in groups. This hypotension was easily treated by incremental dose of mephentermine without any sequels. Hypotension was seen in 2 cases in group R, 3 cases in group R-C15 and 5 cases in group R-C30. Bradycardia was seen in 1 case in group R-C15 and 2 cases in group R-C30. There were no statistically significant differences in systolic BP, MAP and pulse rate in all groups. Clonidine can decrease blood pressure by inhibiting preganglionic sympathetic neural activity in the spinal cord. 
Clonidine can also decrease blood pressure by action in the brain stem, which can be reached after neuraxial administration by systemic redistribution or cephalad spread in cerebrospinal fluid. This may be explained by pharmacology and mechanism of action of clonidine. Intrathecal injection of local anesthetic decreases mean arterial pressure and sympathetic outflow, presumably by blocking axonal transmission along spinal roots and nerves. Various studies have been performed to evaluate the effects of bupivacaine and ropivacaine administration on blood pressure. The results of our study in this regards are also similar to study done by Gonul Sagiroglu et al. De Kock et al reported a statistically significant reduction of MBP in a study in which 45 $\mu \mathrm{g}$ and $75 \mu \mathrm{g}$ clonidine was added to $8 \mathrm{mg}$ of intrathecal ropivacaine ${ }^{[4]}$.

Other adverse effect like shivering, nausea, bradycardia were also observed in few patients but they have no significant difference between two groups.In our study, respiratory depression was not observed in any of the cases. Our study coincides with Hayashi et al. They reported that clonidine does not cause respiratory depression or a decrease in Oxygen saturation ${ }^{[13]}$.

The present study encompasses the study of spinal anaesthesia in patients undergoing lower limb surgery in respect to onset and duration of sensory and motor blockade, highest level of sensory block, duration of analgesia, hemodynamic effects and adverse effects.

\section{Conclusions}

On the basis of results obtained in the study, the following conclusions were made:-

1) The mean time of onset of sensory block was similar in all groups. ( $p>0.05)$

2) The mean time to achieve highest level of sensory block was similar in all the groups. The highest level of sensory block was higher with more dose of clonidine.

3) The mean time of sensory block to regression upto L1 dermatome was earlier in ropivacaine group than both clonidine added groups which was significant, but there was no significant difference between groupRC15 and group R-C30. ( $\mathrm{P}>0.068)$

4) The mean time to onset of motor block was similar in all the groups.

5) Mean duration of motor blockade increased significantly in clonidine added to ropivacaine groups but statistically there was no significant difference between group RC15 \& group R-C30 (P>0.05)

6) Mean duration of complete analgesia and mean duration of effective analgesia increased significa-ntly in clonidine added to ropivacaine groups(more the dose of clonidine, greater the increase in analgesia duration). $(\mathrm{p}<0.05)$

7) No significant change in pulse rate and mean arterial pressure in all the groups.

8) No significant difference in the incidence of hypotension, bradycardia, nausea, and shivering in all the groups. Other adverse effect like vomiting pruritus, urinary retention headache, sedation and respiratory depression were not observed in any case.

To conclude, the addition of clonidine to intrathecal ropivacaine increased the duration of sensory and motor blockade, and the duration of analgesia without affecting haemodynamics significantly and without any significant incidence of adverse effects.

\section{References}

1. Hampl KL, Schneider MC, Ummenhoffer W, Drewe J: Transient neurologic symptoms after spinal anesthesia. AnesthAnalg 1995; 81:1148-53.

2. Harada Y, Nishioka K, Kitahata LM. Visceral antinociceptive effects of spinal clonidine combined with Morphine, (D Pen2, D - Pen5) enkephalin or U50, 488H. Anesthesiology 1995; 83(2):344-352.

3. Aydınl I. Ropivakain. AnesteziDergisi1997; 5:143-146.

4. De Kock M, Gautier P, Fanard L, et al Intrathecal ropivacaine and clonidine for ambulatoryknee arthroscopy. Anesthesiology 2001; 94: 574-8. 
5. Xin-zhong Chen et al Dose-response study of spinal hyperbaric ropivacaine for cesareansection [J Zhejiang Univ SCIENCE B 20067 (12):992- 997].

6. Ying Y. Lee.Spinal ropivacaine for lower limb surgery. A dose response study. [Anaesthesia \& Analgesia 2007:105(520-523)].

7. Gonul Sagiroglu, The Effects of Adding Various Doses of Clonidine to Ropivacaine in Spinal Anesthesia- EAJM: 41, December 2009

8. Racle JP, Benkhadra A, Poy JY, Gleizal B. Prolongation of isobaric bupivacaine spinal anesthesia with epinephrine and clonidine for hip surgery in the elderly. AnesthAnalg 1987; 66: 442-6.

9. Mc Namee DA, Parks L, Mc Clelland AM, et al. Intrathecal ropivacaine for total hiparthroplasty: double-blind comparative studywith isobaric $7.5 \% \mathrm{mg} \mathrm{ml}-1$ and 10 mgml-1solutions. Br J Anaesth 2001; 87: 74

10. Van Kleef JW, Veering B, Burm A. Spinal anesthesia with ropivacaine: a double-blind study on the efficacy and safety of $0.5 \%$ and $0.75 \%$ solutions in patients undergoing minor lower limb surgery. Anesth Analg 1994; 78:1125-3

11. S KurdiMadhuri et al Use of Ropivacaine intrathecally. J Anaesthesiol Clin Pharmacolv. 26(4); Oct-Dec 2010.

12. Rodrigo A, Aghajanian GK. Opiate- and alpha2 -adrenoceptor-induced hyperpolarizetions of locus ceruleus neurons in brain slices: Reversal by cyclic adenosine 3':5'monophosphate analogues. J Neurosci 1985; 5: 235.

13. Hayashi Y, Maze M. Alpha2- adrenoceptor agonist and anaesthesia. $\mathrm{Br} \mathrm{J}$ Anaesth 1993;71: 108-18. 